\title{
LAS INTERVENCIONES DE CONSERVACIÓN DE MONUMENTOS ${ }^{1}$
}

\section{AL CONMEMORARSE EL CUARTO CENTENARIO DE LA FUNDACIÓN ESPAÑOLA DEL CUSCO EN 1934}

Roberto Samanéz Argumedo², Mario R. Castillo Centeno (†) ${ }^{3}$, Pavel Rodríguez Jordán4, María Elena Quispe Ricalde ${ }^{5}$, Germán Zecenarro Benavente ${ }^{6}$.

\section{RESUMEN}

Con motivo del IV Centenario de la Fundación Española de Cusco y la iniciativa de un parlamentario cusqueño, se aprobó un significativo presupuesto para intervenirsus monumentos arqueológicos junto con edificaciones representativas del virreinato y diversas obras públicas, oportunidad que permitió ejecutar los primeros trabajos de restauración en Cusco; interviniéndose de este modo los principales monumentos de la ciudad y su región. El presente estudio devela panorámicamente este momento olvidado de la historia de la ciudad y sus monumentos, evidenciando acciones realizadas en el marco del pensamiento y los ideales de los cusqueños de la época. La información hallada y recuperada es muy valiosa. PALABRAS CLAVE: conservación de monumentos, incanismo, autenticidad, arqueología cusqueña

\section{ABSTRACT}

\begin{abstract}
Commemorating the Fourth centenary of the Spanish foundation of Cusco in 1934, at the initiative of a parliamentary from this city, the National Government approved a significant budget and promulgates laws to intervene the Prehispanic monuments of Cusco together with some Colonial buildings and various public Works for the city, propitious moment that allowed the first interventions of architectural restoration in the city, intervening in this way the main monuments of the city and its región. In a general review, this research reveals now forgotten moment in the history of the city and its monuments, recovering the various actions taken in the thought and the ideals from de cusquenian people of that time. The found and retrieved information is very valuable. KEYWORDS: heritage conservation, "incanismo", authenticity, archaeology in Cusco.
\end{abstract}

1 Con la publicación del presente trabajo, queremos rendir un justo homenaje a la memoria de quien en vida fue el MSc. Arquitecto Mario R. Castillo Centeno, amigo noble y profesional distinguido con quien elaboramos esta investigación. Destacamos su valiosa contribución dedicada a la docencia universitaria, a la práctica restaurativa y a la conservación del Patrimonio cultural cusqueño, así como a su obra escrita, plasmada en diversos artículos, revistas especializadas, publicaciones colectivas y libros.

2 MSc. Arquitecto.

3 MSc. Arquitecto.

4 MSc. Arquitecto. E-mail: rodriguezjordan@yahoo.es

Arquitecta.

6 Arquitecto. E-mail: germanyumi@yahoo.es 
a historia de la conservación y
restauración de bienes culturales en Cusco inicia con trabajos de intervención en distintos monumentos de la ciudad y su dilatada región, que involucraron edificaciones emblemáticas con carácter tanto arqueológico como histórico, así como obras en los principales espacios urbanos de la antigua ciudad. En cuanto a la actuación en estructuras arquitectónicas con carácter arqueológico, este período es todavía oscuro por la ausencia en aquel tiempo, de estudios sobre lo ocurrido en momentos en que las investigaciones aún desconocían el extenso pasado prehispánico de la sociedad y cultura cusqueñas.

El presente trabajo de investigación indaga de manera panorámica sobre los móviles políticos, culturales y tecnológicos que generaron las primeras intervenciones de monumentos en el Cusco, identificando las obras y verificando las acciones,

Figura 1. Centro Histórico del Cusco. Imagen G.Z.B.

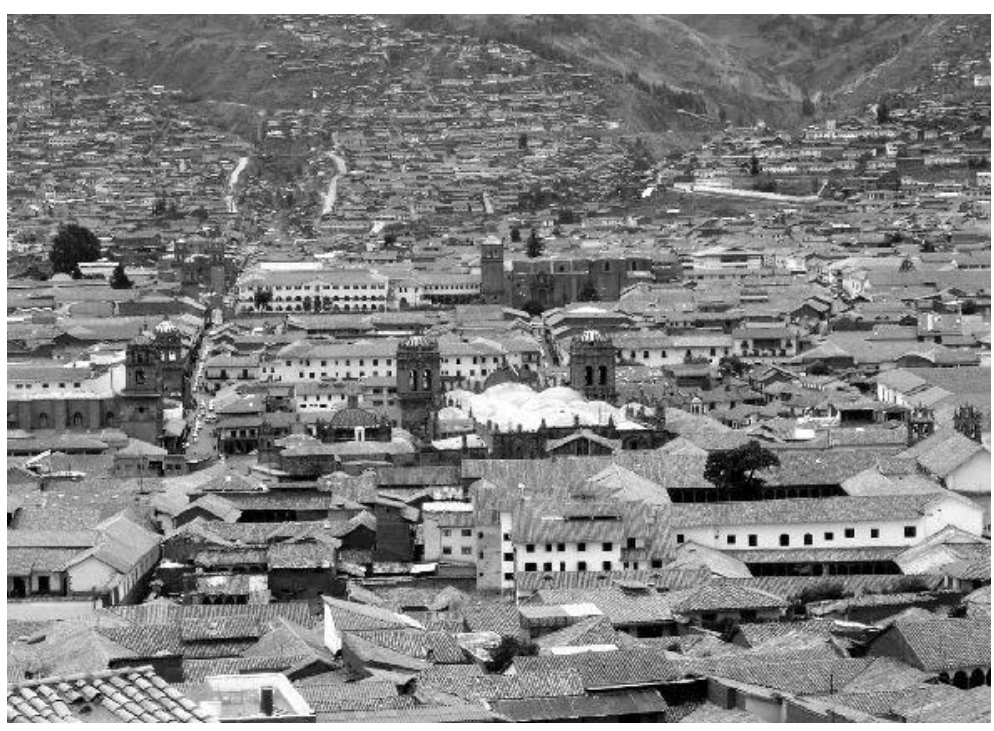

contrastando con trabajos de archivo en informes y publicaciones de época.

\section{ANTECEDENTES}

Poco se conoce de los precedentes en restauración y conservación de monumentos en Cusco. El XV Congreso de Americanistas celebrado en Buenos Aires, motivó a que el 23 de enero de 1933 — a petición del diputado cusqueño Félix Cosío-, se promulgara la Ley 7688 que reconocía a Cusco como "Capital Arqueológica de Sudamérica" (figura 1), lo cual otorgó una renovada oportunidad de impulso a su imagen como centro importante del país en cuanto a turismo, historia y arqueología andina. Junto a este reconocimiento surgió la celebración del IV Centenario de la fundación de la ciudad. Posiblemente estas circunstancias fueron los móviles fundamentales que dieron inicio a las actividades de conservación de los monumentos arqueológicos y virreinales, participando renombrados políticos e intelectuales cusqueños que impulsaron la dación de leyes e instrumentos legales que posibilitaron el apoyo del gobierno para una serie de proyectos dirigidos a consolidar el carácter de la ciudad como centro turístico y eje de estudios arqueológicos e históricos.

\section{LA INTERVENCIÓN DE LOS MONUMENTOS ARQUEOLÓGICOS}

\section{Por iniciativa del} parlamentario Víctor J. Guevara, en 1933 el gobierno aprobó un presupuesto a ser invertido en un programa de actividades para celebrar los 400 años de la Fundación Española del Cusco. Además de la creación de un Instituto arqueológico, se destinaron recursos para la limpieza, reparación y "escombramiento" de los principales monumentos arqueológicos del Cusco y sus inmediaciones. (figura 2). 
Un comité técnico dirigido por el Dr. Luis E. Valcárcel e integrado por el arquitecto Emilio Harth-Terré, el fotógrafo Abraham Guillén, entre otros, se completó con ingenieros, topógrafos, dibujantes, además de personal administrativo. En la ejecución de los trabajos se emplearon casi más de 1,200 trabajadores (Valcárcel 1981: 290).

Durante las labores de remoción se hallaron objetos de cerámica Inca, elementos líticos y ornamentos de cobre y plata, que al parecer no tuvieron registros claros ni asociaciones con sus contextos. No se reportaron evidencias de ocupaciones preincas - aspectos todavía desconocidos en aquel tiempo en cuanto a su nomenclatura y cronología-, ni vestigios de la etapa inicial de la Colonia. Se llevaron a cabo remociones de tierra y liberación de estructuras en Saqsaywaman (figura 3), y se hicieron por primera vez trabajos en Q'enqo, Tambomachay (figura 4), Tarawasi y Machupiqchu.

\section{Para el cuidado y} conservación de los objetos se instaló el Instituto Arqueológico del Cusco, para lo cual se compró la casa de Antonio Lorena en la calle Tigre, acondicionándose para tal fin. Se inauguró en agosto de 1934 y más adelante se convirtió en el Museo de Arqueología de la Universidad del Cusco.

Existe información dispersa sobre las intervenciones y hallazgos. El Banco Italiano de Lima divulgó una Guía sobre
Figura 2. Saqsaywaman. Muros del Templo dedicado al Sol. Imagen G.Z.B.

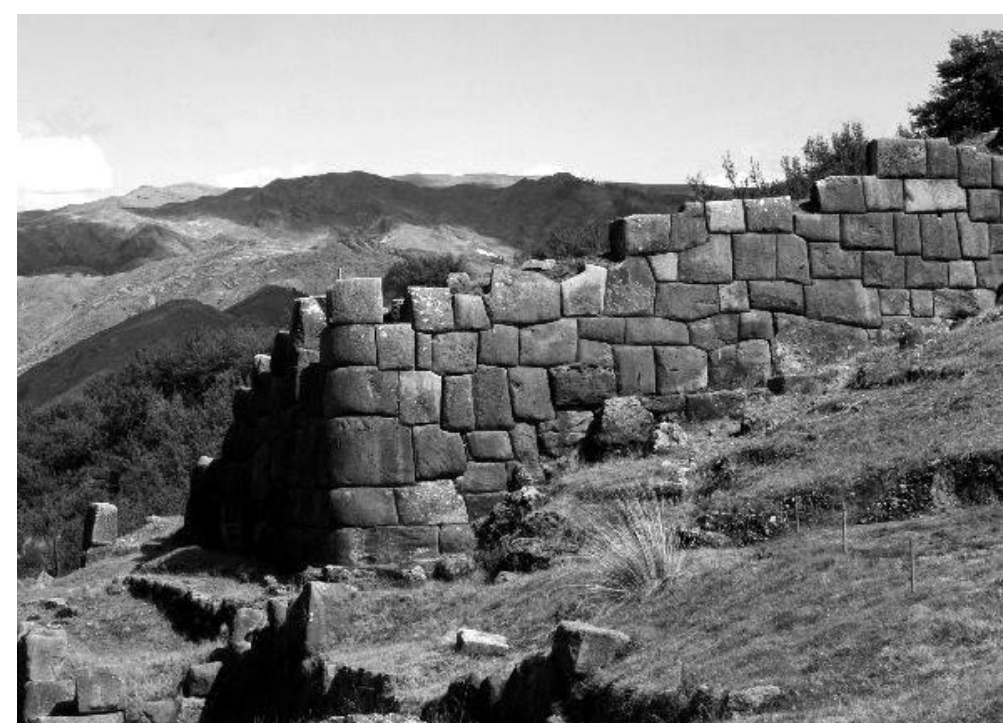

Figura 3. Saqsaywaman. Imagen G.Z.B.

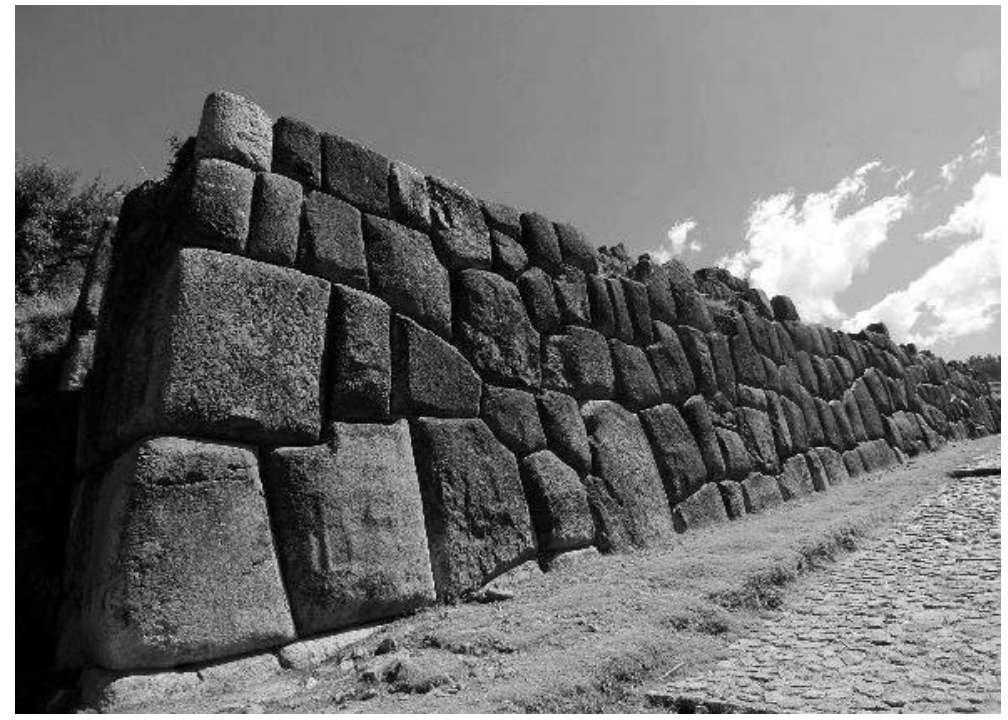

Figura 4. Tambomachay. Imagen G.Z.B.

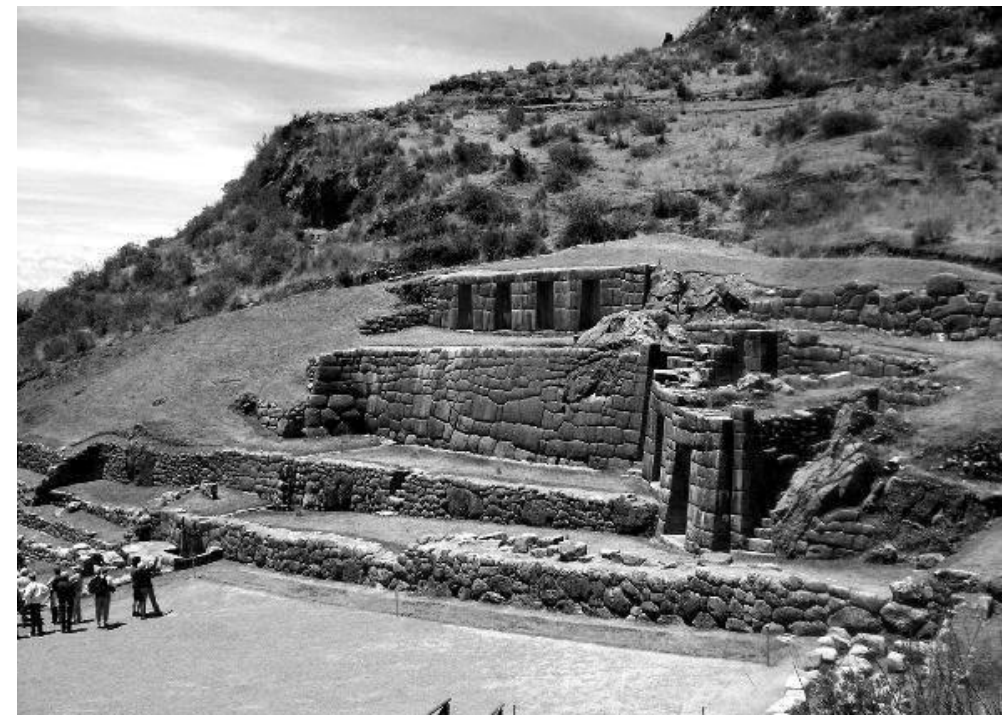


Cusco, y en 1933, la revista del Museo Nacional estuvo dedicada al IV Centenario de la Fundación Española del Cusco. A más de las publicaciones realizadas, no existen estudios sobre este momento importante de la historia de la restauración de los monumentos, salvada por breves pero valiosos datos que se hallan en los archivos del antiguo Patronato del Cusco, el Instituto de Arqueología de la Universidad Nacional de San Antonio Abad del Cusco, el Banco de Crédito de Lima, el Museo Nacional y los diarios de época del Cusco.

Sin embargo, la historia de la arqueología del Cusco desconoce estos aspectos. A la fecha no se han identificado a cabalidad los sectores intervenidos de los monumentos, tampoco cuales fueron estas intervenciones, sus técnicas y procedimientos, o los recursos materiales y humanos que se aplicaron, toda vez que dichos aspectos se encontraban en un estado primario de desarrollo; la Carta de Atenas, que permitió contar con pautas esenciales en el tratamiento de los monumentos, todavía no estaba difundida y la arqueología de Cusco desconocía la presencia de tradiciones culturales anteriores a los Incas, que J. H. Rowe daría a conocer recién en 1948 y 1952.

\section{LA COMISIÓN DEL IV CENTENARIO}

La Ley No7798 promulgada el 13 de septiembre de 1933, estableció la celebración del IV Centenario de la Fundación Española de la ciudad del Cusco, así como su lanzamiento oficial como Capital Arqueológica de Sudamérica, reconocimiento dado en el Congreso de Americanistas desarrollado en Argentina en 1933. La promulgada Ley además instauró la fundación del Instituto Arqueológico.

El presupuesto designado para tales efectos encaminó un conjunto de obras de variada naturaleza que generaron un inusitado entusiasmo local. El Cusco fue el escenario de intervenciones diversas, tales como trabajos de limpieza y consolidación en conjuntos arqueológicos, obras nuevas como la construcción y reparación de carreteras y puentes para la accesibilidad a determinadas "ruinas", así como la edificación y refacción de edificios públicos emblemáticos, conjuntamente con obras de pavimentación de calles, mejoramiento de puentes y la canalización de ríos. Todo ello fue posible gracias a una minuciosa organización que tuvo como cabeza a un Comité central del cual se desprendían comisiones, subcomisiones y secciones, así como diversos comités.

Participaron de estas comisiones numerosas personalidades del medio local, al igual que equipos técnicos con personal comisionado. Es importante señalar la contribución de la Junta Departamental Pro Desocupados, encargada de diversas tareas, principalmente de la pavimentación de calles.

El programa no solo contemplaba la inauguración de obras nuevas y de restauración, sino que involucraba actos artísticos y culturales, como la exposición de objetos de arte colonial religioso, concursos de música, canto y coreografía, certámenes de artes plásticas y aplicadas, conferencias, congresos, abarcando también la publicación de revistas. Por su parte, el Comité de Certámenes emitía circulares para la prensa extranjera americana en demanda de "adhesión espiritual" a las fiestas del IV Centenario, solicitando además que se dediquen ediciones extraordinarias con ese motivo. Ciertamente, la conmemoración del IV Centenario constituyó un acontecimiento que desató efervescencia en la colectividad cusqueña, generando un vivo interés por la recuperación y entendimiento del pasado prehispánico y la revaloración del sentimiento indigenista. En aquella época fue común advertir a través de los diarios y revistas locales, la circulación de manifiestos, ensayos y artículos, alusivos al legado incaico y la cuestión indígena desde perspectivas de corte social, económico, cultural y artístico.

No cabe duda que dentro de la estructura organizativa del IV Centenario, fue la Comisión Técnica la que tuvo una importancia 
superlativa y destacada labor. La presidía el Dr. Luis E. Valcárcel, quien estaba al tanto de lo ocurría a través de informes y otros documentos técnicos y administrativos, que las diferentes comisiones le cursaban regularmente.

\section{PROGRAMA DE INTERVENCIONES}

En el marco de la Ley 7798 de fecha 13 de septiembre de 1933 (figura 5), el Gobierno peruano destinó la suma de seiscientos mil soles de oro de los productos rendidos por el Decreto Ley $\mathrm{N}^{\circ}$ 7103 que creó contribuciones especiales pro desocupados, para atender una serie de obras y la organización y desarrollo de actividades encaminadas a destacar la importancia, con carácter nacional, del magno acontecimiento. Así se definieron y programaron las siguientes acciones:

-Un certamen histórico, artístico y cultural.

- Una feria para la venta de productos de la región.

—Fundación del Instituto Arqueológico.

- Construcción de caminos carreteros a Machupiqchu y Pisaq.

-Organización de una exposición agrícola e industrial.

Figura 6. Correspondencia entre el Dr. Rafael Aguilar y el Dr. Luis E. Valcárcel. Archivo del Museo Inka de la Universidad Nacional de San Antonio Abad del Cusco. Imagen G.Z.B.

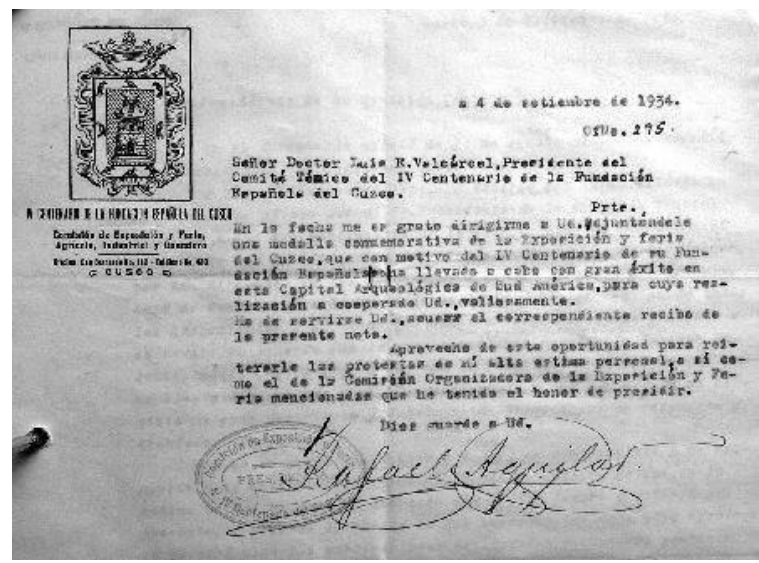

- Inauguración oficial del Cusco como Capital arqueológica de Sudamérica.

- Inauguración de carreteras, escuelas, obras públicas y termas.

-Canalización del río Huatanay.

-Conclusión del Hospital del Cusco.

-Refacción del Palacio Prefectural (Antiguo Cabildo).

—Reparación de las "ruinas".

De la misma manera, esta Ley autorizó la emisión de estampillas conmemorativas de aquella fecha, cuyo producto fue invertido íntegramente en la construcción de locales escolares en cada distrito del Departamento del Cusco.

Figura 7. Documento aprobando los trabajos de intervención en contextos arqueológicos del Cusco. Archivo del Museo Inka de la Universidad Nacional de San Antonio Abad del Cusco. Imagen G.Z.B.

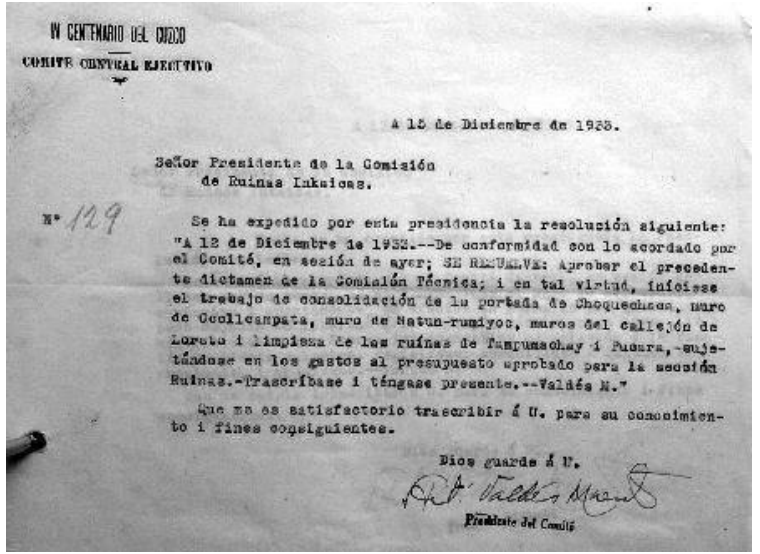




\section{OBRAS EJECUTADAS}

La Comisión de Obras Municipales, presidida por Rafael Aguilar, alcalde del Concejo Provincial y Presidente de las Comisiones de construcción del nuevo Hospital, Obras Municipales, Exposición y Feria (figura 6), reporta un conjunto de asuntos relativos a los diversos frentes de trabajo y la ejecución de obra propiamente dicha.

De acuerdo a la Sub comisión de obras coloniales, las obras abarcaron los templos de San Sebastián, Belén y San Pedro, considerando trabajos de refacción y resanes en muros, revoques y empaste de bóvedas.
Ligado a la Sub Comisión de Ruinas, destacan los trabajos desarrollados en Saqsaywaman (figura 7), objeto de una importante labor realizada por Luis E. Valcárcel (Valcárcel 1981: 290).

Adicionalmente se enfatizan las obras de consolidación en Ollantaytambo y en Machupiqchu, con la limpieza de sus edificaciones y la construcción del pequeño hotel y camino carretero.

Basados en los informes, las siguientes tablas evidencian las características resaltantes de los diferentes trabajos efectuados entre los años 1933 y 1934.

Intervenciones desarrolladas como parte de las celebraciones del Cuarto Centenario de la Fundación Española del Cusco, Periodo 1933 - 1934. Programa de Intervención: SECCIÓN OBRAS MUNICIPALES

\begin{tabular}{|c|c|c|c|}
\hline OBRA & OBSERVACIONES & RESPONSABLES & FECHA \\
\hline \multirow{2}{*}{$\begin{array}{l}\text { Canalización del } \\
\text { río Huatanay, } \\
\text { sección Plateros }\end{array}$} & $\begin{array}{l}\text { Noviembre } 1933 \text {, se destina presupuesto para la canalización } \\
\text { del río Huatanay. }\end{array}$ & $\begin{array}{l}\text { Moisés León } \\
\text { Comité Central Ejecutivo }\end{array}$ & \multirow{7}{*}{$\begin{array}{l}1933- \\
1934\end{array}$} \\
\hline & $\begin{array}{l}\text { El } 12 \text { de marzo de } 1934 \text { se inician las obras preliminares entre el } \\
\text { Puente de la Compañía y la Calle del Medio: } \\
\text { Retiro de escusados situados a los costados del río. } \\
\text { Arrendamiento de patios ubicados en las casas construidas a las } \\
\text { orillas del río, donde se abrieron puertas de acceso al río. } \\
\text { Construcción de la bóveda ("abovedamiento"). }\end{array}$ & $\begin{array}{l}\text { Rafael Aguilar } \\
\text { Alcalde del Concejo Provincial } \\
\text { y Presidente de la Comisión } \\
\text { Obras Municipales, } \\
\text { Construcción del Nuevo } \\
\text { Hospital y Exposición Agrícola } \\
\text { e Industrial. }\end{array}$ & \\
\hline $\begin{array}{l}\text { Canalización del } \\
\text { río Huatanay, } \\
\text { sección Portal } \\
\text { Espinar }\end{array}$ & $\begin{array}{l}\text { Armaduras de hierro para vaciar el concreto. } \\
\text { Recolección de piedra del río, arena y cascajo, acarreamiento a } \\
\text { la obra. } \\
\text { Construcción de cimbras. }\end{array}$ & \multirow[t]{5}{*}{$\begin{array}{l}\text { En abril de } 1934 \text { se contrata } \\
\text { como auxiliar al Ing. Justo } \\
\text { León Peralta. }\end{array}$} & \\
\hline $\begin{array}{l}\text { Puente de La } \\
\text { Almudena }\end{array}$ & $\begin{array}{l}\text { En noviembre de } 1933 \text {, el Comité Central resuelve la } \\
\text { reconstrucción del muro derruido en el Puente de La Almudena. } \\
\text { Elaboración de adobes para la construcción de una pared, } \\
\text { empedrado de calle y vereda que conducen al Hospital Central. }\end{array}$ & & \\
\hline $\begin{array}{l}\text { Puente } \\
\text { Chunchulmayo }\end{array}$ & $\begin{array}{l}\text { Construcción de muro de concreto sobre el río, en el sector que } \\
\text { conduce al Asilo de Ancianos. }\end{array}$ & & \\
\hline $\begin{array}{l}\text { Canalización } \\
\text { Tullumayo }\end{array}$ & $\begin{array}{l}\text { Marzo de } 1934 \text {, ejecución de la limpieza del río para facilitar el } \\
\text { alcantarillado. }\end{array}$ & & \\
\hline Puente del Rosario & Marzo de 1934 , obras de relleno. & & \\
\hline $\begin{array}{l}\text { Nuevo Hospital } \\
\text { mixto de Belén }\end{array}$ & $\begin{array}{l}\text { Trabajos de cimentación. } \\
\text { Construcción de muros de adobe. } \\
\text { Cercos y muros de la fachada. } \\
\text { Verja de hierro de la puerta principal. } \\
\text { Pabellón de Administración. } \\
\text { Pabellón de medicina para hombres. }\end{array}$ & $\begin{array}{l}\text { Ingeniero Cáceres. } \\
\text { Director de los trabajos. }\end{array}$ & \multirow[t]{3}{*}{$\begin{array}{l}1933- \\
-1934\end{array}$} \\
\hline $\begin{array}{l}\text { Cantera de } \\
\text { San Blas }\end{array}$ & Acarreo de piedras para las obras del Hospital mixto. & & \\
\hline $\begin{array}{l}\text { Exposición y } \\
\text { Feria de } \\
\text { Kuichipunko }\end{array}$ & Arreglo de los pabellones & & \\
\hline
\end{tabular}


Cuarto Centenario de la Fundación Española del Cusco. Periodo 1933 - 1934.

Programa de intervención: SECCIÓN DE INTERVENCIÓN DE RUINAS INCAICAS.

\begin{tabular}{|c|c|c|c|}
\hline OBRA & OBSERVACIONES & $\begin{array}{l}\text { RESPONSABLES O } \\
\text { PERSONAJES PROTAGÓNICOS }\end{array}$ & FECHA \\
\hline \multirow[t]{2}{*}{$\begin{array}{l}\text { Puente y Hotel de } \\
\text { Machupiqchu }\end{array}$} & Metrado de los pabellones A y B & Arq. Emilio Harth Terré & $\begin{array}{l}\text { Marzo } \\
1933 \\
\end{array}$ \\
\hline & $\begin{array}{l}\text { Diciembre 1933. Autorización inicio de los trabajos del puente y } \\
\text { camino de Machupicchu. } \\
\text { Enero 1934. Encargo del proyecto a Harth Terré. } \\
\text { Febrero 1934. Conclusión del expediente técnico y proyecto } \\
\text { definitivo del Hotel en Machupiqchu. }\end{array}$ & & $\begin{array}{l}\text { Junio } \\
1934\end{array}$ \\
\hline \multirow[t]{2}{*}{$\begin{array}{l}\text { Muro de la calle } \\
\text { Loreto }\end{array}$} & $\begin{array}{l}12 \text { de diciembre de 1933. Aprobación del trabajo de } \\
\text { consolidación. } \\
\text { Inspección al Monasterio realizada el } 18 \text { de enero 1934, con la } \\
\text { participación, entre otros, de Valcárcel y el Monseñor Vicario. } \\
\text { Reposición de elementos líticos labrados para el muro exterior de Loreto. } \\
\text { El Monasterio entrega } 85 \text { piedras labradas de procedencia prehispánica. }\end{array}$ & $\begin{array}{l}\text { Sor Margarita del Corazón de } \\
\text { Jesús. O. P. } \\
\text { Priora del Monasterio de Santa } \\
\text { Catalina }\end{array}$ & $\begin{array}{l}\text { Marzo } \\
1934\end{array}$ \\
\hline & $\begin{array}{l}\text { Reparación de muros de la calle Loreto } \\
\text { En mayo de 1935, la Sociedad de Artesanos construye el edificio de } \\
\text { su Escuela Nocturna sobre la explanada de Amarucancha, abriendo " } \\
\text { puerta de acceso aprovechando una falla del muro de la calle } \\
\text { Loreto, estableciendo servidumbre de paso sin autorización legal. } \\
\text { Con motivo de la obra se colocaron centenares de adobes sobre los } \\
\text { muros incaicos, poniendo en peligro su estabilidad. Estas obras } \\
\text { afectaron a los trabajos efectuados por el Comité del IV Centenario. }\end{array}$ & $\begin{array}{l}\text { Distribución de fondos según } \\
\text { Artículo } 5^{\circ} \text { de la Ley } 7798 \\
\text { "Ruinas", presentado por } \\
\text { Valcárcel, Director del Museo } \\
\text { Nacional, al Comité Central } \\
\text { sEjecutivo de las Fiestas Pro } \\
\text { Cuarto Centenario. }\end{array}$ & $\begin{array}{l}\text { Nov. } \\
1933 \\
\text { Mayo } \\
1935\end{array}$ \\
\hline $\begin{array}{l}\text { Calle } \\
\text { Choquechaca }\end{array}$ & $\begin{array}{l}\text { Reparación de las portadas. } \\
\text { Intención para realizar expropiaciones de casas Incaicas. } \\
12 \text { de diciembre de } 1933 \text {. Se aprueban trabajos de consolidación } \\
\text { de la portada de Choquechaca. }\end{array}$ & \multirow{4}{*}{$\begin{array}{l}\text { Distribución de fondos según } \\
\text { Artículo } 5^{\circ} \text { de la Ley } 7798 \\
\text { "Ruinas", presentado por } \\
\text {-Valcárcel, Director del Museo } \\
\text { Nacional, al Comité Central } \\
\text { Ejecutivo de las Fiestas Pro } \\
\text { Cuarto Centenario. }\end{array}$} & \multirow{4}{*}{$\begin{array}{l}1933 \\
1934\end{array}$} \\
\hline Sapantiana & Trabajos de limpieza & & \\
\hline $\begin{array}{l}\text { Calle } \\
\text { Hatunrumiyoq }\end{array}$ & $\begin{array}{l}\text { Reparación. } \\
12 \text { de diciembre de 1933. Se aprueban trabajos de consolidación. }\end{array}$ & & \\
\hline Ruinas de Puquín & Desmonte y reparación. & & \\
\hline $\begin{array}{l}\text { Plazoleta de } \\
\text { San Cristóbal } \\
\text { Collcampata }\end{array}$ & $\begin{array}{l}\text { Marzo de 1930. Como parte de los trabajos de la Plazoleta de } \\
\text { San Cristóbal, se desmonta irresponsablemente un sector del } \\
\text { andén Inca, poniéndose en riesgo la estabilidad del conjunto. } \\
12 \text { de diciembre de } 1933 \text {. Aprobación de la consolidación del } \\
\text { muro de Collcampata. } \\
\text { Reparación general de los muros de Colcampata en } 1934 \text {. } \\
\text { Diciembre 1933. Mensura y tasación de la "Casa quinta } \\
\text { Ccollccampata", por el Ing. Felipe Guzmán. Ofrecimiento de ve } \\
\text { para el Instituto Arqueológico. }\end{array}$ & $\begin{array}{l}\text { Levantamiento de planos Ing. } \\
\text { Felipe Guzmán. } \\
\text { Juan de Luchi Lomellini y familia. } \\
\text { Propietarios de la Casa quinta } \\
\text { Collcampata. }\end{array}$ & $\begin{array}{l}1930 \\
1933 \\
1934\end{array}$ \\
\hline
\end{tabular}

Muros incaicos de Se recomienda el arreglo de los siguientes callejones (en función a Distribución de fondos según la ciudad y $\quad$ su visita turística): Loreto; Awajpinta; Romeritos; Ladrillo; Siete espacios urbanos. Culebras; La Conquista; Cabracancha; última cuadra de Artículo $5^{\circ}$ de la Ley 7798 Choquechaca; Hatunrumiyoc; Atau-calle.

"Ruinas", presentado por

Se recomienda descubrir el puente incaico de Santa Teresa. Valcárcel, Director del Museo Nacional, al Comité Central Febrero de 1934. Proyecto de la Plaza de Santa Teresa del Arq. Emilio Ejecutivo de las Fiestas Pro Harth Terré, incluyendo el levantamiento y plano del puente incaico. Cuarto Centenario.

Febrero de 1934, se cuenta con el Proyecto de la Plaza del Cabildo, elaborado por Arq. Emilio Harth Terré (plano de arreglo de los jardines). 1934. Elaboración del Plano Regulador del Cusco, realizado por Arq. Emilio Harth Terré, considerando el Informe preliminar para la realización de la obra y aspectos urbanos que deben estudiarse en el proyecto preliminar y en el definitivo.

Estudio del Arq. Emilio Harth Terré para la catalogación de piedras de los muros incas de la ciudad, determinando estilos. Incluyó un modelo de hoja de catalogación. 1934.

Informe del Arq. Emilio Harth Terré sobre la arquitectura cusqueña y su Catalogación. 1934.

En base al informe emitido por el Ing. Carlos Ugarte, en diciembre de 1933 se aprueba la pavimentación de los portales de la ciudad, con locetas de cemento. 


\begin{tabular}{|c|c|c|c|}
\hline Templo del Sol & $\begin{array}{l}\text { Construcción del arco de entrada. } \\
\text { Labrado de piezas líticas. } \\
\text { Rectificación del lindero original del Coricancha, } \\
\text { avanzándolo sobre la calzada, a fin de no afectar la } \\
\text { integridad del muro de piedra del andén Inca (el documento } \\
\text { tiene adjunto un croquis elaborado por Harth Terré). }\end{array}$ & $\begin{array}{l}\text { Emilio Harth Terré. Arquitecto } \\
\text { Asesor de la Comisión Técnica } \\
\text { del IV Centenario. }\end{array}$ & $\begin{array}{l}1933 \\
1934\end{array}$ \\
\hline Saqsaywaman & $\begin{array}{l}\text { Noviembre 1933. Aprobación mejoramiento de la carretera a } \\
\text { Saqsaywaman. } \\
\text { Mayo de 1934. El Ing. Antonio Oliart remite a la Comisión } \\
\text { Técnica del IV Centenario, un plano de la ciudad del Cuzco } \\
\text { y de las Ruinas de Saqsaywaman, así como un Mapa } \\
\text { Histórico del Departamento del Cuzco. } \\
\text { Reparación de muros. } \\
\text { Expropiación de terrenos. } \\
\text { Proyecto del Arq. Emilio Harth Terré para la construcción de } \\
\text { un albergue en Saqsaywaman. 1934. } \\
\text { Trabajos de redescubrimiento, especialmente en la cima de } \\
\text { la colina. Sector Muyocmarca, Sayacmarca y Paucarmarca. } \\
\text { Recintos y explanadas, portadas, acueductos. }\end{array}$ & $\begin{array}{l}\text { Luis E. Valcárcel } \\
\text { Ing. Antonio Oliart } \\
\text { Arq. Emilio Harth Terré }\end{array}$ & $\begin{array}{l}1933 \\
1934\end{array}$ \\
\hline Tambomachay & $\begin{array}{l}\text { Reparaciones. } \\
12 \text { de diciembre de 1933. Aprobación trabajos de } \\
\text { consolidación. }\end{array}$ & \multirow{6}{*}{$\begin{array}{l}\text { Distribución de fondos según } \\
\text { Artículo } 5^{\circ} \text { de la Ley } 7798 \\
\text { "Ruinas", presentado por } \\
\text {-Valcárcel, Director del Museo } \\
\text { Nacional, al Comité Central } \\
\text { Ejecutivo de las Fiestas Pro } \\
\text {-Cuarto Centenario }\end{array}$} & \multirow{7}{*}{$\begin{array}{l}1933 \\
1934\end{array}$} \\
\hline $\begin{array}{l}\text { Carretera } \\
\text { Saqsaywaman - } \\
\text { Tambomachay }\end{array}$ & Prolongación de la carretera & & \\
\hline $\begin{array}{l}\text { Pucara } \\
\text { (Pucapucara) }\end{array}$ & $\begin{array}{l}\text { Expropiación de terrenos. } \\
\text { Reparaciones. } \\
12 \text { de diciembre de 1933. Aprobación trabajos de } \\
\text { consolidación. }\end{array}$ & & \\
\hline Hanan Qosqo & $\begin{array}{l}\text { Limpieza general. } \\
\text { Carretera. }\end{array}$ & & \\
\hline $\begin{array}{l}\text { Restablecimiento } \\
\text { de caminos } \\
\text { incaicos }\end{array}$ & $\begin{array}{l}\text { Camino inca a Yucay. } \\
\text { Camino inca a Calca. } \\
\text { Camino inca a Huchuy Qosqo. }\end{array}$ & & \\
\hline $\begin{array}{l}\text { Callachaca, } \\
\text { Quillahuata, } \\
\text { Pumamarca, } \\
\text { Ticapata }\end{array}$ & $\begin{array}{l}\text { Diciembre de } 1933 \text {. Obra de reparación del camino a } \\
\text { Pumamarca. } \\
\text { Limpieza y reparación. } \\
\text { Trabajos en caminos. }\end{array}$ & & \\
\hline Pisac & $\begin{array}{l}\text { Construcción carretera a Intihuatana de Pisac. } \\
\text { Enero 1934. Trabajos en Intihuatana: } \\
\text { Limpieza y desentierro de muros. }\end{array}$ & $\begin{array}{l}\text { Trabaja el Ing. Julio Villa Acuña. } \\
\text { Ayudante de Ingeniería Adolfo } \\
\text { Rivero (plano de Pisac) }\end{array}$ & \\
\hline Ollantaytambo & $\begin{array}{l}\text { Trabajos especiales de desmonte. } \\
\text { Reparación. } \\
\text { Planos y estudios realizados por Arq. Emilio Harth Terré en } \\
\text { 1934: Fortaleza de Pumamarca, Palacio de Kelluraccay, Plaza } \\
\text { Manyaraqui, Estudio de la casa de las puertas de tres jambas, } \\
\text { Croquis topográfico de Ollantaytambo. Escala 1:1000, Plano } \\
\text { de las casas de Choquetacarpu, Estudio de la arquitectura de } \\
\text { las casas. }\end{array}$ & $\begin{array}{l}\text { Arq. Emilio Harth Terré. } \\
\text { En marzo de } 1934 \text { trabajan en } \\
\text { Ollantaytambo los Ings. Alfredo } \\
\text { Pancorbo y Raez. }\end{array}$ & \\
\hline Maras & Reparación de andenes. & & \\
\hline Yucay & Reparación de edificios. & & 1933 \\
\hline Chinchero & Incluye Templo. & & 1934 \\
\hline Tarawasi & Reparación de los andenes. & $\begin{array}{l}\text { Marzo 1934. Trabaja en } \\
\text { Tarawasi el Ing. Aranibar. }\end{array}$ & \\
\hline $\begin{array}{l}\text { Piquillacta, } \\
\text { Choquepucyo, } \\
\text { Tipón, Kañarracay, } \\
\text { ruinas de } \\
\text { Quispicanchi. }\end{array}$ & $\begin{array}{l}\text { Limpieza. } \\
\text { Reparación. }\end{array}$ & $\begin{array}{l}\text { Marzo 1934. Trabaja en } \\
\text { Piquillacta el Ing. Gohring. }\end{array}$ & \\
\hline Rumicollca & $\begin{array}{l}\text { Limpieza. } \\
\text { Reparación. }\end{array}$ & $\begin{array}{l}\text { Marzo 1934. Trabaja en } \\
\text { Rumicolca el Ing. Rocha. }\end{array}$ & \\
\hline
\end{tabular}


Templo de Cacha, Desmonte.

San Pedro, Racchi Reparación.
Marzo 1934. Trabaja en San

Pedro de Cacha, el Ing. A.

Ugarte $\mathrm{V}$.

Fortaleza de Wacra Diciembre 1933. Rafael Aguilar pone de manifiesto la

Pucara en petición del Concejo de Pomacanchi para obtener un

Acomayo. presupuesto de S/. 10,000 soles para las reparaciones de la fortaleza de Huacra Pucara.

Anta, Canas, Reparación y limpieza general de los diversos grupos

Espinar, Paruro, arqueológicos ubicados en dichas provincias.

Urubamba.

Machupiqchu y Trabajos especiales completos.

ruinas próximas Expropiación.

Construcción de Hotel, albergues y refugios.

Dotación de agua.

El 02 de diciembre de 1933 se aprueba mediante resolución

el presupuesto para efectuar diferentes obras en

Machupiqchu.

Se recomienda igualmente, utilizar los servicios de Antonio

Santander, descubridor del camino a Huayna Piqchu, así como la rehabilitación del mismo.

Vilcabamba

19 de diciembre de 1933. Aprobación de la propuesta para Ingeniero C. Bües.

el levantamiento del mapa arqueológico de la región de

Vilcabamba (acompañado de fotografías y croquis). Dicho

levantamiento fue realizado por el Ingeniero C. Bües.
Levantamiento del plano

arqueológico

Intervenciones desarrolladas como parte de las celebraciones del Cuarto Centenario de la Fundación Española del Cusco. Periodo 1933 - 1934. Programa de intervención: SUB COMISIÓN DE CONSTRUCCIONES COLONIALES

\begin{tabular}{llll}
\hline Obra & Observaciones & $\begin{array}{l}\text { Responsables o personajes } \\
\text { protagónicos }\end{array}$ & Fecha \\
\hline $\begin{array}{l}\text { Sociedad de } \\
\text { Artesanos }\end{array}$ & $\begin{array}{l}\text { Colocación de mampara de vidrios bajo el arco de la } \\
\text { antigua Capilla de San Ignacio de Loyola. }\end{array}$ & $\cdot$ \\
\hline Templos coloniales & Reparaciones en los templos de la ciudad: & \\
& Basílica Catedral. & $\begin{array}{l}\text { Encargado Ing. Benigno } \\
\text { Pacheco Scheiñer }\end{array}$ \\
& Templo La Matriz (El Triunfo). & \\
& Templo de Jesús y María. & & 1934 \\
& Templo de La Compañía. & \\
& Templo de Belén (encargado Ing. Cáceres F.) & \\
& Templo de San Pedro. & \\
& Templo de San Antonio. & \\
& Templo de San Sebastián. & \\
\hline
\end{tabular}

Reconstrucción de Diciembre 1933. Encargo del proyecto al Arq. Emilio Harth Planos de obra, estudios

Cabildo y Casa Terré.

Prefectural
Febrero 1934. Se concluye Expediente técnico y proyecto definitivo del edificio ubicado en la Plazoleta Regocijo y calle Santa Teresa.

Informe del Arq. Emilio Harth Terré sobre el Instituto Arqueológico, y las propiedades ofrecidas en venta para el mismo. 1934.

Marzo de 1934. Continúan las demoliciones del antiguo edificio, incluidas unas arquerías de concreto armado construidas por la Guardia Civil, elementos no contemplados en el proyecto del Arq. Emilio Harth Terré. preliminares. Arq. Emilio

Harth Terré.

Encargado Ing. Miguel A.

González 
Basílica Catedral Obras de albañilería.

del Cusco
Pisos del Altar Mayor.

Obras de carpintería.

Trabajos en la Sacristía (Museo de la Basílica)

J. B. Espinosa, Presidente del Capítulo de la Santa

Basílica Catedral del Cuzco, y el Vicario Capitular

Monseñor Juan Antonio Casanova solicitan el cambio del

piso de la Catedral con locetas labradas de dos colores

alternados, sea en mármol o con piedras pulidas; así

como las escalinatas del Altar mayor.

Igualmente la Presidencia del Capítulo Eclesiástico

solicita fondos para concluir el edificio contiguo a

Jesús y María, llamado "Antigua Curia", destinado a

Sala de Sesiones Capitulares.
J. B. Espinosa, Presidente del

Capítulo de la Santa Basílica Catedral del Cuzco.

Vicario Capitular Monseñor Juan Antonio Casanova

Basílica Catedral Trabajos en la acequia detrás del Sagrario.

del Cusco

\begin{tabular}{|c|c|c|c|}
\hline $\begin{array}{l}\text { Restauración, } \\
\text { trabajos de } \\
\text { limpieza y }\end{array}$ & $\begin{array}{l}\text { La Comisión Técnica aprueba las acciones de limpieza y } \\
\text { remiendos de lienzos coloniales, hasta por un total de } \\
\text { doscientos metros cuadrados. }\end{array}$ & $\begin{array}{l}\text { Pintor Francisco Olazo } \\
\text { Pintor Francisco De Santo. }\end{array}$ & $\begin{array}{l}\text { Diciembre } \\
1933\end{array}$ \\
\hline $\begin{array}{l}\text { necesarios de } \\
\text { cuadros coloniales } \\
\text { existentes en }\end{array}$ & $\begin{array}{l}\text { Se informa sobre daños ocasionados por la intervención } \\
\text { restaurativa. }\end{array}$ & & $\begin{array}{l}\text { Marzo - } \\
\text { Junio } \\
1934\end{array}$ \\
\hline
\end{tabular}

templos y

conventos del

Cusco.

Restauración de

lienzos de la

Catedral.
Los miembros de la Sub Comisión de Monumentos

Coloniales, Dr. Juan Antonio Casanova y Domingo Velazco

Astete, seleccionan lienzos antiguos con mérito, para su

limpieza y refresco.

Esta Sub Comisión presenta el 29 de enero de 1934 una

lista de lienzos seleccionados de los conventos de Santo

Domingo $\left(420 \mathrm{~m}^{2}\right)$ y de la Merced $\left(416 \mathrm{~m}^{2}\right)$.

En enero 1934, bajo la supervisión del artista Juan Manuel Juan Manuel Figueroa Aznar Figueroa Aznar, se encarga dicho trabajo a Agustín Rivero, Agustín Rivero Ricalde Julio Gutiérrez, Luis Cáceres y Mariano Fuentes Lira.

Eanseñor Juan Antonio Casanova solicita la intervención de los lienzos del transepto de la Catedral.

Aprobación del contrato a los pintores Agustín Rivero Ricalde; Julio Gutiérrez Loayza; Luís Cáceres; y Mariano Fuentes Lira, para limpiar y refrescar lienzos al óleo.

Prof. Natalicio Delgado R. Escultor de la Real Academia Albertini de Bellas Artes de Turín, presenta su propuesta para restaurar ocho lienzos.

(No existe partida presupuestal para tal trabajo)
Dr. Juan Antonio Casanova.

Dr. Domingo Velazco Astete

(1)


pensamiento que sus habitantes buscan imponer a nivel nacional, con sentido de reivindicación histórica. La efeméride del

IV Centenario representa la materialización de la presencia nacional de los cusqueños y el afianzamiento del pensamiento "indigenista" e "incanista" en el país.

\section{El "Indigenismo" e "Incanismo"} como corrientes de pensamiento, ponderan al habitante andino y su rico pasado, como base de identidad nacional y fuente de desarrollo local, regional y nacional.

La buena presentación y conservación de los monumentos arqueológicos de Cusco surge de la necesidad de evidenciar ante el país y el mundo, la magnificencia de su pasado, considerando por primera vez que el turismo podría ser una fuente económica importante.

Es notoria la preocupación existente en la época para recuperar también el patrimonio histórico, expresado principalmente en la arquitectura religiosa virreinal.

Significativas obras públicas en espacios urbanos emblemáticos de la ciudad - que inclusive han llegado hasta la fecha-, así como la ejecución de vías que articulaban

los monumentos con los ejes viales existentes en aquel tiempo, tienen su data de origen

en los procesos de intervención efectuados con motivo del IV Centenario. En estas obras se hacen evidentes los criterios para mejorar el contexto o marco circundante de los monumentos, su integración a circuitos prestablecidos, y la vocación turística que se estaba pretendiendo para el Cusco y su región.

Las bibliotecas del Museo Nacional y el archivo del Museo Inka de la Universidad Nacional San Antonio Abad del Cusco, poseen documentación valiosa que soporta toda la actividad referida a las intervenciones y diversas actividades de la celebración del IV Centenario de la Fundación Española de Cusco durante los años 1933 y 1934.

\section{SUGERENCIAS}

Es recomendable inventariar y catalogar la documentación relativa a la formación del Instituto de Arqueología que se halla en los depósitos del Museo Inka, por ser ésta única e importante para la conservación de la memoria histórica de esta institución.

Impulsar trabajos de reconocimiento arqueológico de las intervenciones ejecutadas en 1933 y 1934, mediante prospecciones epiteliales, difundiendo los resultados por ser valiosos para quienes intervienen en el patrimonio local.

\section{REFERENCIAS}

Castillo Centeno, Mario (1991). Alejandro Deustua y la Arquitectura. En Contextos. Año 1. N $\mathrm{N}^{\circ}$ 1. Avances de investigación. Universidad Nacional de Ingeniería. Lima.

García, José Uriel (1937). El nuevo indio. Ensayos indianistas sobre la sierra sur peruana. H. G. Rozas, Cusco.

Instituto Nacional de Cultura. Departamental Cusco (1989). Carta de Atenas. En Cartas Internacionales de Conservación del Patrimonio Cultural. Págs. 9-15. Jefatura de la Unidad de Investigación. Cusco.

Instituto Nacional de Cultura. Departamental Cusco (2007). Carta de Atenas. En Documentos Fundamentales para el Patrimonio Cultural. Textos internacionales para su recuperación, repatriación, conservación, protección y difusión. Págs. 133-135. Lima.

Kuón, Elizabeth; Gutiérrez, Rodrigo; Gutiérrez, Ramón; y Viñuales, Graciela (2009). Cuzco - Buenos Aires. Ruta de Intelectualidad Americana (1900-1950). Fondo editorial de la Universidad de San Martín de Porres.

Pardo, Luis A. (1970). La fortaleza de Sacsayhuamán. Revista Sacsaywaman. Patronato Departamental de Arqueología del Cuzco. Cusco.

Rénique, José Luis (2013). Luis E. Valcárcel: Del Indigenismo Cusqueño a la Antropología Peruana. Ediciones Copé - Petroperú. Fondo editorial del Congreso del Perú. Instituto de Estudios Peruanos.

Tamayo Herrera, José (1978). Historia Social del Cuzco Republicano. Industrial gráfica S.A. Lima.

Valcárcel Vizcarra, Luis Eduardo (1933). Sajsawaman redescubierto. Revista del Museo Nacional. Tomo III, Nos. 1 - 2; pp. 3-36. Lima. 
Valcárcel Vizcarra, Luis Eduardo (1981). Memorias. Instituto de Estudios Peruanos. Editado por José Matos Mar, José Deustua C. y José Luis Rénique. Lima.

\section{Archivos}

Universidad Nacional de San Antonio Abad del Cusco. Archivo documentario del Museo Inka.

Diario El Comercio del Cusco. Años 1933 - 1934. 